\title{
An Investigation of Implementing Different Control Options to Improve Power System Transient Stability
}

\author{
Sahar R. Al-Sakini, Athraa S. Hasan and Isam K. Saedi \\ Department of Electromechanical Engineering, University of Technology, Baghdad, Iraq
}

\begin{abstract}
A transient stability is widely accepted as an important aspect in upgrading and designing power system. This study presents a transient stability analysis for IEEE-9 bus power system using Power World Simulator (PWS). This study investigates the stability by using Static Var Compensator (SVC) and operating the generators with $90 \%$ of their rated power. Then, the effect of SVC and generator control on power system transient stability will be compared. Results from simulation show that the effectiveness of operating generators with $90 \%$ of rated power and SVC on the transient stability of power system.
\end{abstract}

$\underline{\text { Key words: Power system, transient stability, FACTS, SVC, load flow study, critical clearing time, IEEE-9 bus }}$

\section{INTRODUCTION}

Power system stability has been recognized as a challenging and important problem for operating a secure power system, especially, for inter-connected system. When a large disturbance occur, the security of the electrical power system has to be examined. A security of power system depend on stability detailed studies for the system to ensure that the system is operating securely (Mihirig and Wvong, 1989).

A power system is a very complex system consisting of transmission lines, numerous generators, transformers and variety of loads. When an increasing in power demand, most of transmission lines are loaded more than they were planned. At long transmission lines with increased loading, the problems at the state of transient stability and after a main fault can become a limiting factor transmission (Sharma, 2014).

The transient stability in power system depends on; initial operating state and disturbance state. A disturbance changes of the power system such that hereafter disturbance operation at steady state will be different from that prior disturbance.

The development of electrical power system introduce the use of FACTS devices which represent a flexibility at transmission system controllers in electrical power system. The controller FACTS is capable of controlling the electric network conditions at a very fast mode and this feature for the FACTS can be exploited to improve the voltage stability, transient and steady state stabilities for a complex electrical power system (Papic and Zunko, 2002). This properties allow to increase the utilization of existing electric network closer to its loading thermal capacity and obviate the need for construction of new transmission line (Mithulananthan et al., 2003).

The primary function of the SVC is to maintain voltage at a specific buses by mean of reactive power compensation (Hingorani and Gyugyi, 2000). SVC represents the first generation of FACTS device which can control the voltage at the buses to improve the voltage profile of power system. A static VAR compensator have been used at very high performance transient and steady state controller voltage compared with a shunt compensation, used to power swing dampen, to improve the transient stability and to reduce the losses of the system by optimized the control reactive power (Zhou, 1993).

\section{MATERIALS AND METHODS}

FACTS controller: A FACTS controller is a power electronic based system and static equipment which provide control for one or more parameters in $\mathrm{AC}$ transmission system to increase a capability of power transfer and to enhance the controllability (Preeedavichit and Srivtsava, 1998).

A Static VAR Compensator (SVC) is applied by utilizes at transmission applications at many purposes. The first purpose is the fast control of voltage in a network at a weak points. Installations of SVC may be at the end of transmission or at midpoint. SVC are shunt connected static generator/absorbers which output is varied to control the voltage of power system. At a simple shape of SVC which is basically consist of Thyristors Controlled Reactor (L) and Fixed Capacitor (C) ( TCR-FC) as shown in Fig. 1. The coupling transformer is connected

Corresponding Author: Sahar R. Al-Sakini, Department of Electromechanical Engineering, University of Technology, Baghdad, Iraq 


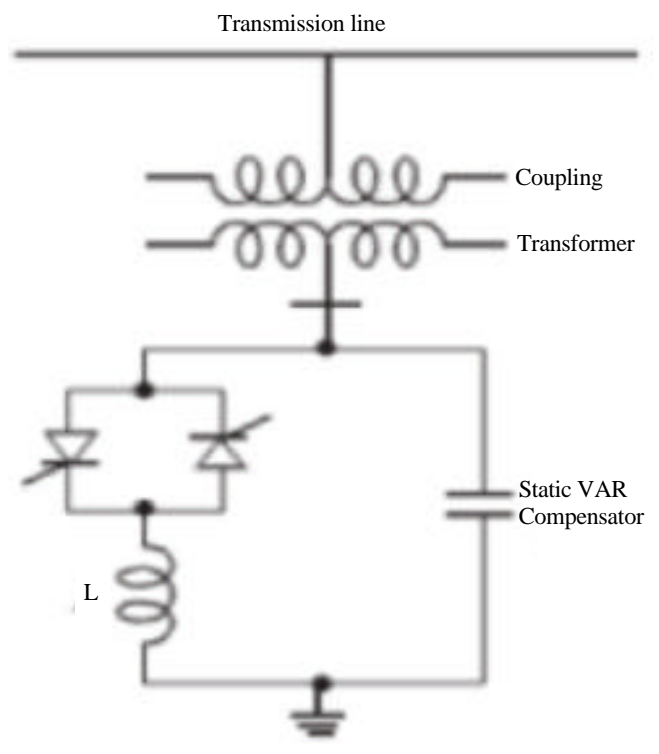

Fig. 1: SVC connected with the transmission line

with SVC and with AC transmission line where the voltage be regulated. The reactance effective of the (TCR-FC) is varied by firing the control angle for the thyristors. A proportional-itegral controller is controlled the firing angle in any point where the voltage of the transmission line in system (Dell Rosso et al., 2003).

A swing equation represent the motion for the rotor of machine relating to torques at the rotor of machine relating to an inertia torque to a resultant for the electrical and mechanical torque at the rotor (Anderson and Fouad, 2002) Eq. 1:

$$
\frac{\mathrm{d}^{2} \delta}{\mathrm{dt}^{2}} \mathrm{Mi}=\mathrm{P}_{\mathrm{mec.i}}-\mathrm{P}_{\mathrm{elc} . \mathrm{i}}
$$

where, $\mathrm{i}=1,2,3,4, \ldots, \mathrm{n}$.

$$
\begin{gathered}
P_{\text {elc.i }}=G_{i i}\left|E_{i}\right|^{2}+\sum_{j=1}^{n}=\left[\left|E_{i}\right|\left|E_{i}\right|\left|G_{i}\right|\left(\cos \left(\delta_{i}-\delta_{j}\right)\right)\right]+ \\
\left|E_{i}\right|\left|E_{i}\right|\left|B_{i j}\right|\left(\sin \left(\delta_{i}-\delta_{j}\right)\right)
\end{gathered}
$$

Where:

$$
\begin{aligned}
& \text {. }=\text { Machine rotor angle } \\
& \mathrm{M}=\text { Machine inertia constant } \\
& \mathrm{P}_{\text {_. }}=\text { Mechanical power in machine } \\
& \mathrm{P}_{-} \quad=\text { Electrical power in machine } \\
& \text { E }=\text { Voltage behind a direct axis }(\mathrm{sec}) \text { for transient }
\end{aligned}
$$

The critical clearing time (tccr) can be found in Eq. 3 (Xue and Pavella, 1993):

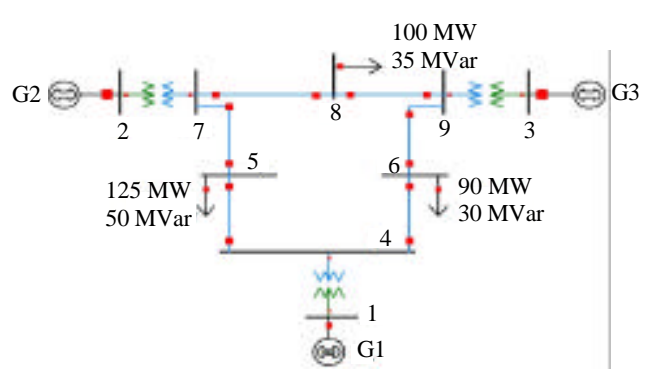

Fig. 2: One line diagram for IEEE-9 bus test system

$$
\operatorname{tccr}=\left[\left(2 \mathrm{M} / \mathrm{w}_{0} \mathrm{P}_{0}\right)\left(\delta_{\mathrm{ccr}}-\delta_{0}\right)\right]^{\frac{1}{2}}
$$

Where:

$$
\begin{array}{ll}
\mathrm{P} . \quad & =\text { Output Power for generator before fault } \\
& =\text { Critical clearing angle } \\
& =\text { Angle of pre-fault } \\
\mathrm{M} & =\text { Inertia constant }
\end{array}
$$

Implementation the Power World Simulator (PWS): Power World Simulator (PWS) 18.0 is used with new interface ribbon and it is advanced version. The steps which are taken to run simulation in PWS for transient stability analysis include:

First step: "Edit Mode" the one line diagram of power system network is drawn and data for all network components are inserted.

Second step: "Switch program", after the network has been drawn and the data entered correctly, switch the program to run mode.

Third step: "Run mode", run the power flow and then find output of each generator, the voltage and angle of each bus bar.

Fourth step: Set the fault location and clearing time to run the case transient stability simulation.

Fifth step: "Stability analysis" find the optimal placement for the FACTS device. In this study, the single line diagram for the simulated system test presented in Fig. 2. The software is used for analysis the transient stability and voltage for 9 bus power system. In this research, the first generator is connected to the first bus "slack bus1" where the second generator connected to bus 2 and the third generator connected to bus 3 . The loads are connected at 5,6 and 8 bus bars as $125 \mathrm{MW}, 90 \mathrm{MW}$ and $100 \mathrm{MW}$, respectivly. According to the kind of plant these can be several load flow cases to explain and study. The goal of this identify 
was find the best and worst conditions of operating. Many solution of load flow used in industry like as a Newton-Raphson, Gauss-siedel and current injection. There is a requirement for one swing bus bar at the network in all load flow algorithms solution.

\section{RESULTS AND DISCUSSION}

Simulation model: The system in Fig. 2 is simulated in PWS where IEEE-9 bus test system is analyzed for transient stability. The results for load flow analysis are listed in Table 1, done by using Newton-Raphson method which are taken at operating related power for all loads and generator.

The rotor angle for generator 1 is $2.5^{\circ}$, generator 2 is $60^{\circ}$ and generator 3 is $57^{\circ}$ which explain the stability state as show in Fig. 3 which represent the relationship between time (sec.) and rotor angle $\left({ }^{\circ}\right)$. The generators data show in Table 2 (Patel et al., 2002). There are three study cases in this research:

First case; transient stability analysis without control: In this case there are no controls applied to improve the transient stability. Three phase solid fault is applied at time $\mathrm{t}=0.1 \mathrm{sec}$. on the line $7-8$ and the critical clearing time was $241 \mathrm{~ms}$ as shown in Fig. 3. As can be seen that generators 2 and 3 are the most affected generators in system. This is because the fault is close to them and they were the most loaded ones in the system. If the critical clearing time for circuit breaker interrupts fault at time beyond $241 \mathrm{msec}$, the system will be unstable as shown in Fig. 5 which explain the time (sec) with rotor angle $\left(^{\circ}\right.$ ) (Fig. 4-6).
Case two; Power system with SVC: In this case, the power system has FACTS devices type SVC which inserted on bus 5,6 and 8 as show in Fig. 7. The SVC inserted on buses to inject VAR locally, so as to bring up the voltage level to a value close to 1.04 p.u.

Table 1: Results for load flow analysis without control

\begin{tabular}{lllllll}
\hline $\begin{array}{l}\text { Bus } \\
\text { No. }\end{array}$ & $\begin{array}{l}\text { Voltage } \\
(\mathrm{Pu})\end{array}$ & $\begin{array}{l}\text { Angle } \\
\left({ }^{\circ}\right)\end{array}$ & $\begin{array}{l}\mathrm{Pg} \\
(\mathrm{MW})\end{array}$ & $\begin{array}{l}\mathrm{PL} \\
(\mathrm{MW})\end{array}$ & $\begin{array}{l}\text { Qg } \\
(\mathrm{MVar})\end{array}$ & $\begin{array}{l}\text { QL } \\
(\mathrm{MVar})\end{array}$ \\
\hline 1 & 1.02 & 0 & 49 & 0 & 62 & 0 \\
2 & 1 & 12.19 & 163 & 0 & 33 & 0 \\
3 & 1 & 8.96 & 109 & 0 & 17 & 0 \\
4 & 0.9851 & -1.62 & 0 & 0 & 0 & 0 \\
5 & 0.944 & -3.05 & 0 & 125 & 0 & 50 \\
6 & 0.9608 & -2.33 & 0 & 90 & 0 & 30 \\
7 & 0.9846 & 6.24 & 0 & 0 & 0 & 0 \\
8 & 0.9702 & 3.4 & 0 & 100 & 0 & 35 \\
9 & 0.992 & 5.27 & 0 & 0 & 0 & 0 \\
\hline
\end{tabular}

Table 2: Generators data

\begin{tabular}{llll}
\hline Generator No. & 1 & 2 & 3 \\
\hline Rated MVA & 247.5 & 192.0 & 128.0 \\
$\mathrm{kV}$ & 16.5 & 18.0 & 13.8 \\
$\mathrm{H}(\mathrm{s})$ & 23.64 & 6.4 & 3.01 \\
Power factor & 1.0 & 0.85 & 0.85 \\
Type & Hydro & Steam & Steam \\
Speed & $180 \mathrm{r} / \mathrm{min}$ & $3600 \mathrm{r} / \mathrm{min}$ & $3600 \mathrm{r} / \mathrm{min}$ \\
$\mathrm{x}_{\mathrm{d}}$ & 0.1460 & 0.8958 & 1.3125 \\
$\mathrm{X}_{\mathrm{d}}{ }^{\prime}$ & 0.0608 & 0.1198 & 0.1813 \\
$\mathrm{x}_{\mathrm{q}}$, & 0.0969 & 0.8645 & 1.2578 \\
$\mathrm{x}_{\mathrm{q}}{ }^{\prime}$ & 0.0969 & 0.1969 & 0.25 \\
$\mathrm{x}_{1}($ leakage) & 0.0336 & 0.0521 & 0.0742 \\
$\mathrm{~T}_{\mathrm{do}}$ & 8.96 & 6.00 & 5.89 \\
$\mathrm{~T}_{\mathrm{qo}}$, & 0 & 0.535 & 0.600 \\
Stored energy & $2364 \mathrm{MWs}$ & $640 \mathrm{MWs}$ & $301 \mathrm{MWs}$ \\
at rated speed & & &
\end{tabular}

Reactance values are in pu on a 10 MVA base. All time constants are in seconds

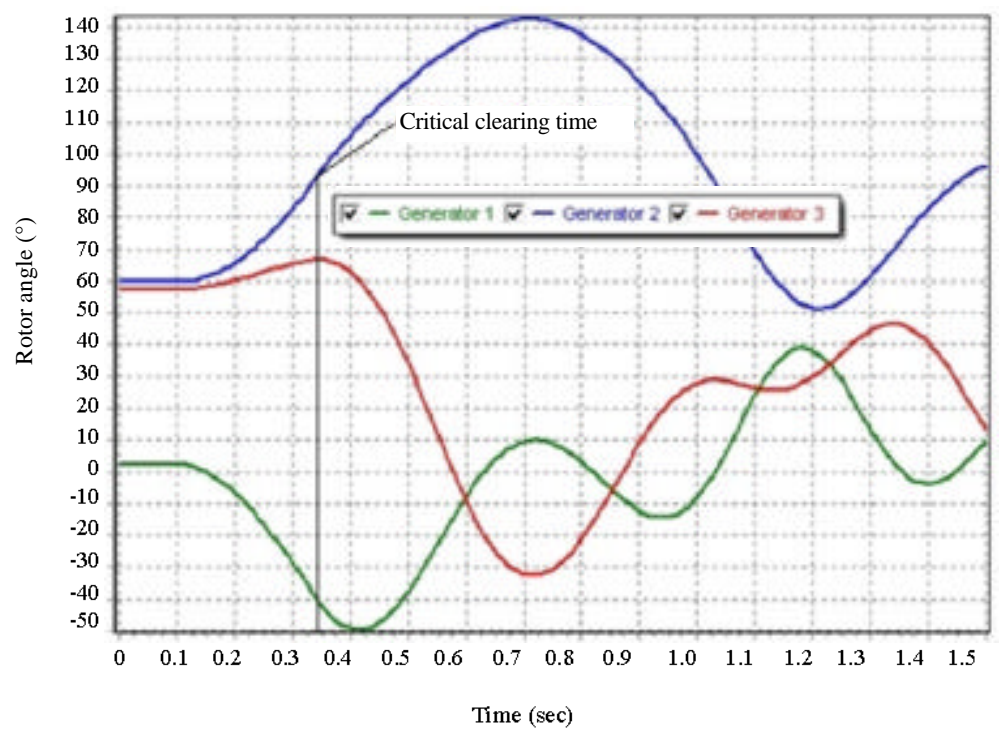

Fig. 3: Rotor angle for a stabile state case 


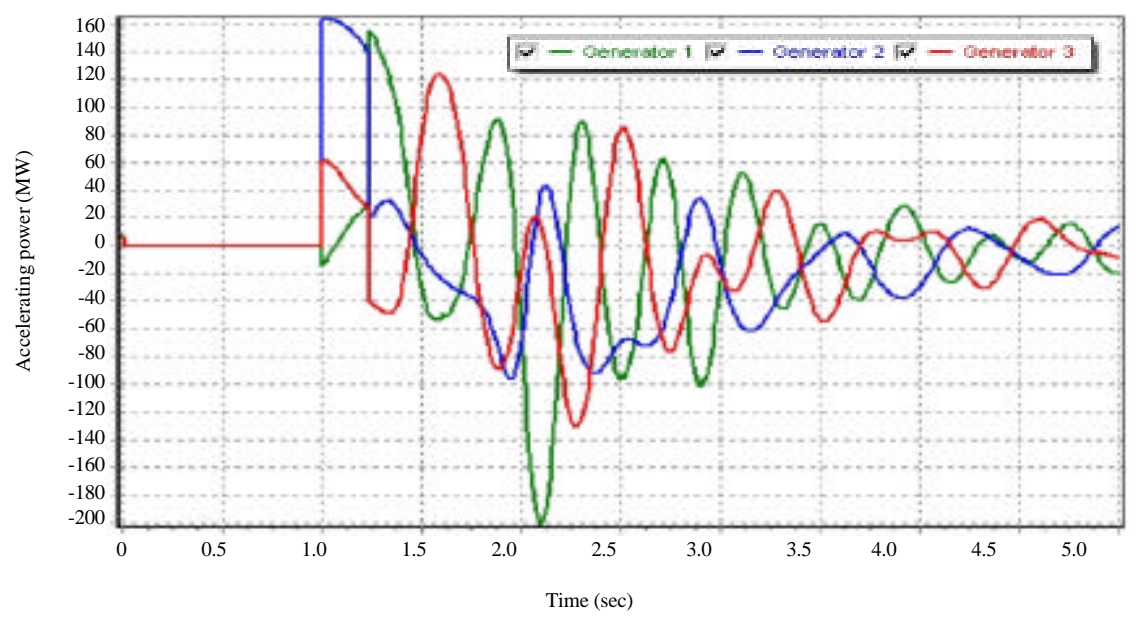

Fig. 4: Accelerating power for a stable state case

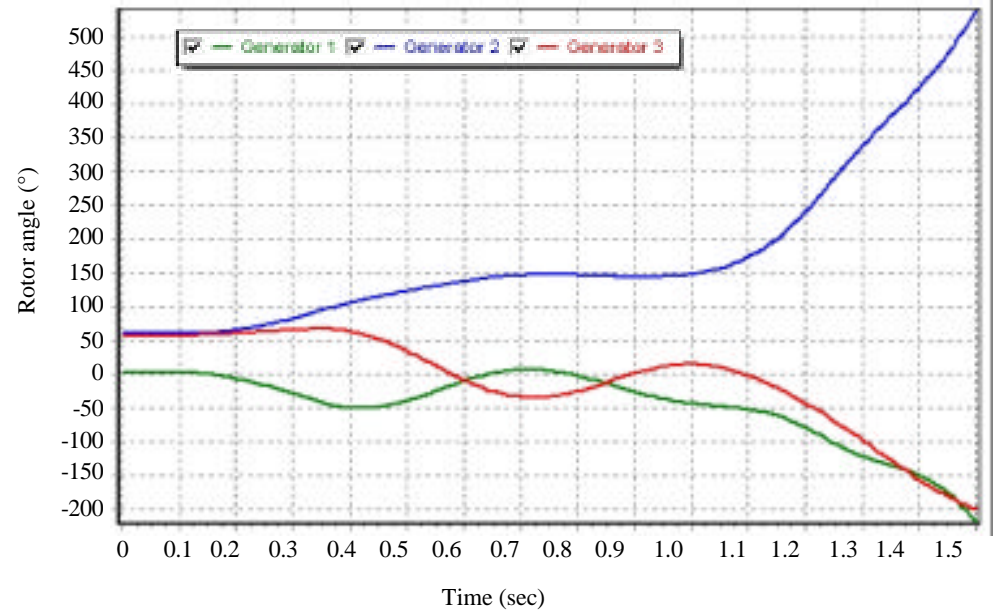

Fig. 5: Rotor angle for unstable system without control

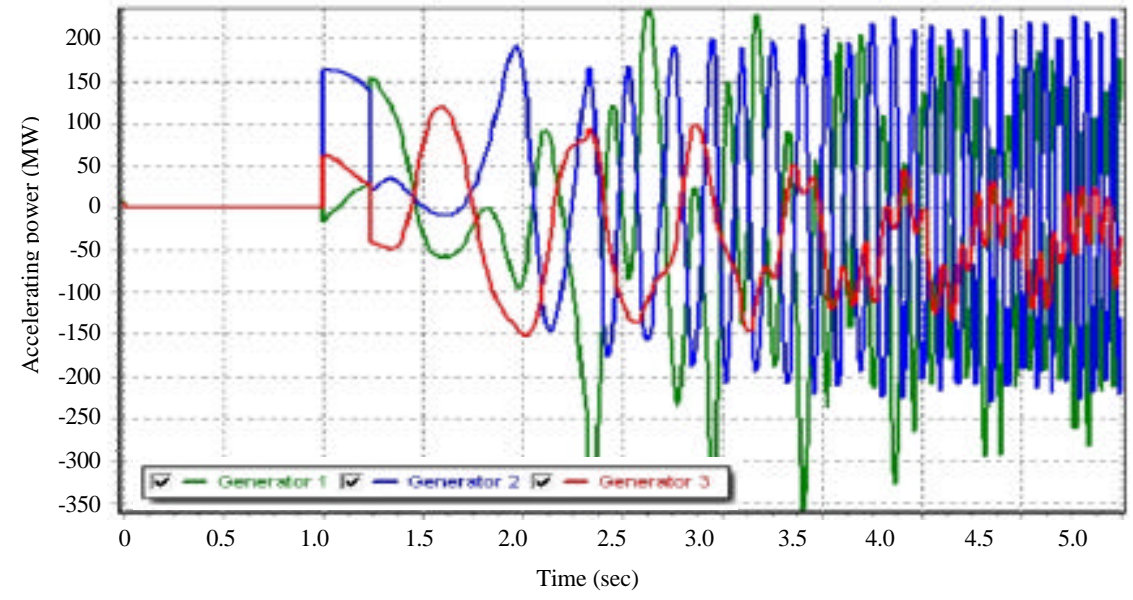

Fig. 6: Accelerating power for unstable system without control 


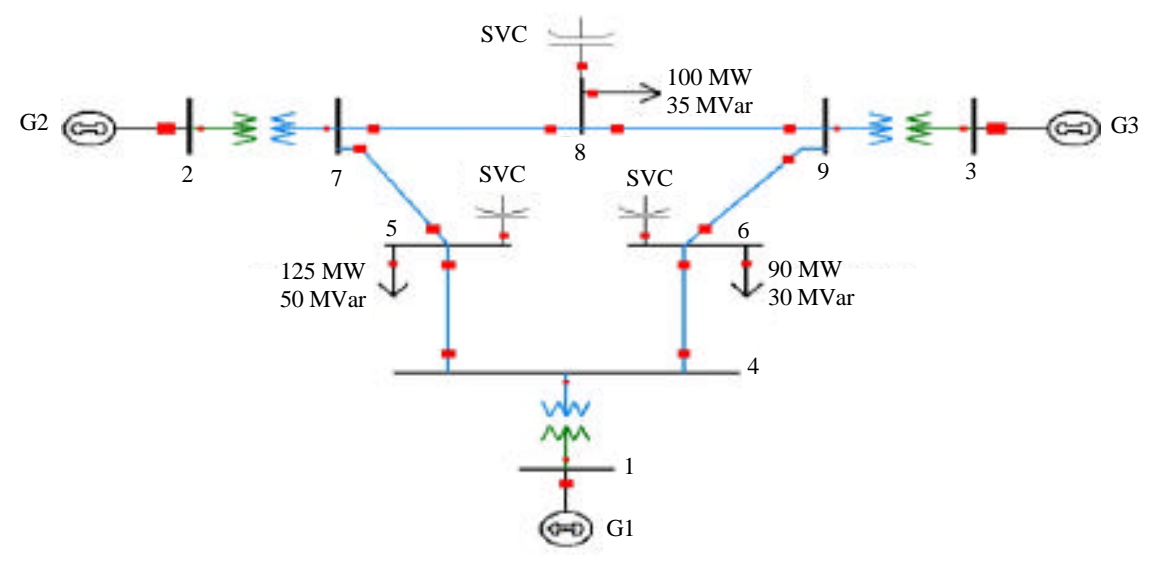

Fig. 7: One line diagram for IEEE-9 bus and generators data with SVC

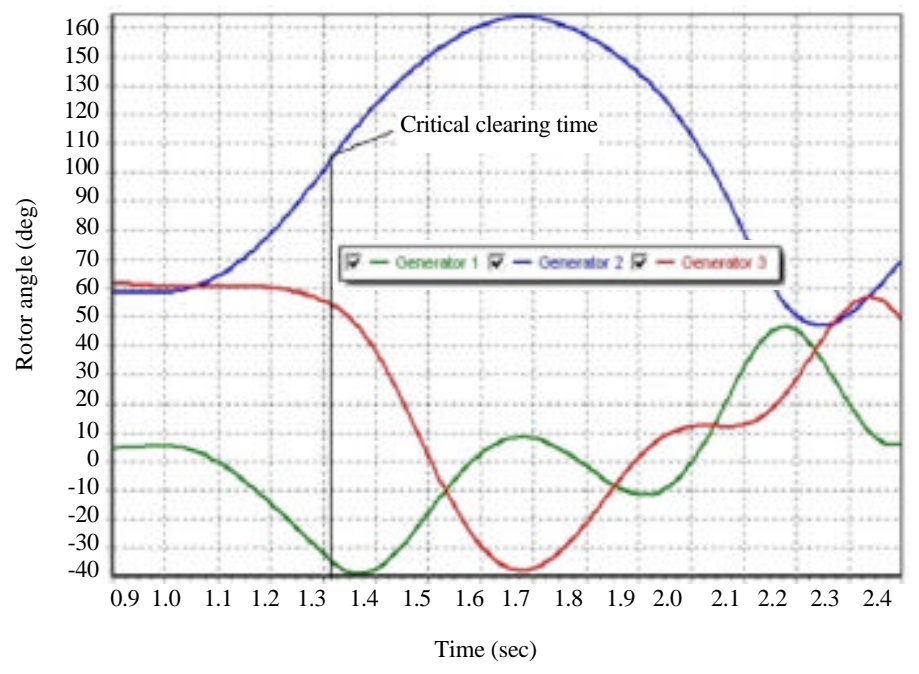

Fig. 8: Rotor angle for the system with SVC

The load flow solution done by using Newton-Raphson method and the results for the network are shown in Table 3 . The three phase solid fault is applied at line 7-8 and the critical clearing time was $315 \mathrm{msec}$ as shown in Fig. 8 which explain the time (sec) with rotor angle $\left({ }^{\circ}\right)$.

Case three; generators output control: In this case generator 2 and 3 are operated with $90 \%$ of their rated output power. The rotor angle of generator $1=4^{\circ}$, generator $2=53.5^{\circ}$ and generator $3=51.5^{\circ}$ as show in Fig. 9 which explain the time (sec.) with the rotor angle. The post fault time has increased to $376 \mathrm{msec}$. The load flow solution done by using Newton-Raphson method and the results are listed in Table 4.

Compression between three cases studies: The compression done between the power system analysis
Table 3: Load flow solution (network with SVC)

\begin{tabular}{lllllll}
$\begin{array}{l}\text { Bus } \\
\text { No. }\end{array}$ & $\begin{array}{l}\text { Voltage } \\
(\mathrm{Pu})\end{array}$ & $\begin{array}{l}\text { Angle } \\
\left({ }^{\circ}\right)\end{array}$ & $\begin{array}{l}\text { Pg } \\
(\mathrm{MW})\end{array}$ & $\begin{array}{l}\mathrm{PL} \\
(\mathrm{MW})\end{array}$ & $\begin{array}{l}\text { Qg } \\
(\mathrm{MVar})\end{array}$ & $\begin{array}{l}\text { QL } \\
(\mathrm{MVar})\end{array}$ \\
\hline 1 & 1.020 & 0 & 49 & 0 & -19 & 0 \\
2 & 1 & 11.40 & 163 & 0 & -31 & 0 \\
3 & 1 & 8.46 & 109 & 0 & -38 & 0 \\
4 & 1.0314 & -1.53 & 0 & 0 & 0 & 0 \\
5 & 1.0328 & -3.02 & 0 & 125 & 74.43 & 50 \\
6 & 1.0350 & -2.43 & 0 & 90 & 51.77 & 30 \\
7 & 1.0245 & 5.69 & 0 & 0 & 0 & 0 \\
8 & 1.0339 & 2.99 & 0 & 100 & 62.6 & 35 \\
9 & 1.0245 & 4.89 & 0 & 0 & 0 & 0 \\
\hline
\end{tabular}

without control, power system with SVC device and power system with generators 2 and 3 operating at $90 \%$ of rated output power as show in Table 5. According to simulation results, a compression is made among the three cases for stability enhancement considering post fault duration/critical clearing time. 


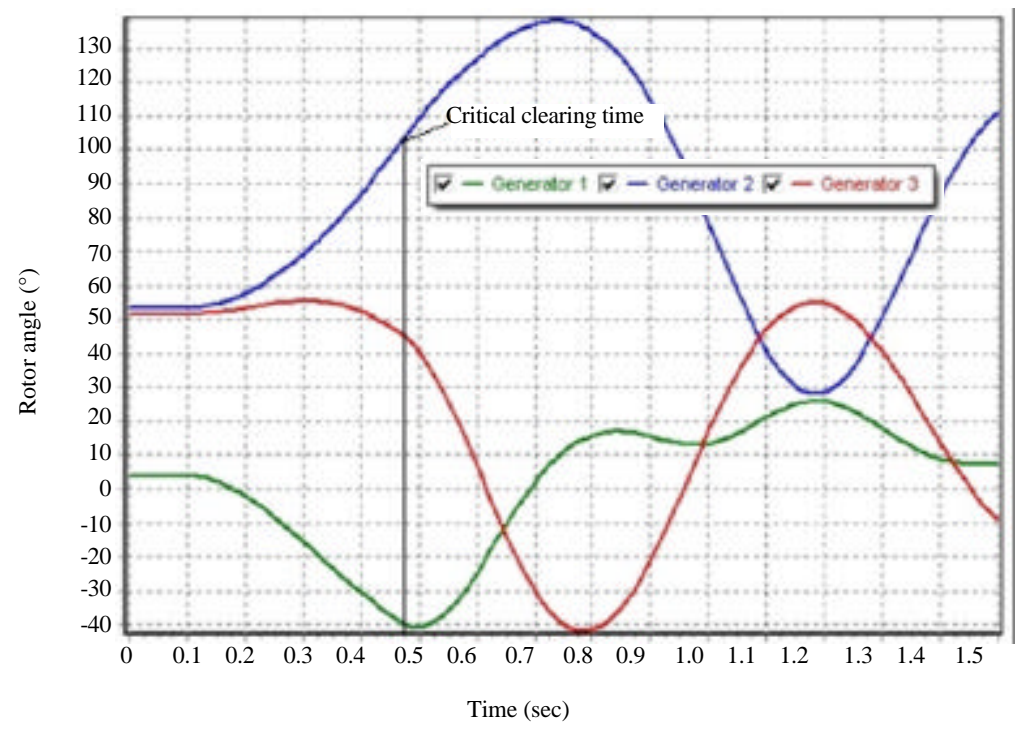

Fig. 9: Rotor angle for the system with generators control

Table 4: Load flow solution with $90 \%$ of rated power

\begin{tabular}{lllllll}
\hline $\begin{array}{l}\text { Bus } \\
\text { No. }\end{array}$ & $\begin{array}{l}\text { Voltage } \\
(\mathrm{Pu})\end{array}$ & $\begin{array}{l}\text { Angle } \\
(\mathrm{Deg})\end{array}$ & $\begin{array}{l}\text { Pg } \\
(\mathrm{MW})\end{array}$ & $\begin{array}{l}\text { PL } \\
(\mathrm{MW})\end{array}$ & $\begin{array}{l}\text { Qg } \\
(\mathrm{MVar})\end{array}$ & $\begin{array}{l}\text { QL } \\
(\mathrm{MVar})\end{array}$ \\
\hline 1 & 1.02 & 0 & 76 & 0 & 59 & 0 \\
2 & 1 & 8.40 & 146 & 0 & 29 & 0 \\
3 & 1 & 5.67 & 98 & 0 & 15 & 0 \\
4 & 0.9879 & -2.49 & 0 & 0 & 0 & 0 \\
5 & 0.9483 & -4.67 & 0 & 125 & 0 & 50 \\
6 & 0.9642 & -3.90 & 0 & 90 & 0 & 30 \\
7 & 0.9861 & 3.09 & 0 & 0 & 0 & 0 \\
8 & 0.9714 & 0.35 & 0 & 100 & 0 & 35 \\
9 & 0.9929 & 2.35 & 0 & 0 & 0 & 0 \\
\hline
\end{tabular}

Table 5: Compression between the three case studies

\begin{tabular}{lll}
\hline Type of system & $\begin{array}{l}\text { Stability } \\
\text { enhancement }\end{array}$ & $\begin{array}{l}\text { Post fault } \\
\text { duration(msec) }\end{array}$ \\
\hline Without control & No & 241 \\
SVC & Yes & 315 \\
$90 \%$ of rated output power & Yes & 376 \\
\hline
\end{tabular}

Results show that the operating loaded generators with $90 \%$ of rated output power is the most effective mitigation measure for stability enhancement.

\section{CONCLUSION}

In this study, the stability in power system is improved by using SVC and generators output control. The system is investigated under three case studies which are no control, SVC control and with generator output control. Then, these case studies are simulated using PWS and the output results are compared. The results of simulation clear that operating generators with $90 \%$ of their rated power output improved power system transient stability through increasing post fault time to $376 \mathrm{msec}$.

\section{REFERENCES}

Anderson, P.M. and A.A. Fouad, 2002. Power System Control and Stability. 2nd Edn., Wiley-IEEE Press, New York, ISBN-13: 978-0471238621, pp: 672.

Dell Rosso, A.D., C.A. Canizares and V.M. Dona, 2003. A study of TCSC controller design for power system stability improvement. IEEE Trans. Power Syst., 18: 1487-1496.

Hingorani, N.G. and L. Gyugyi, 2000. Understanding FACTS Concepts and Technology of Flexible AC Transmission Systems. Understanding FACTS Concepts and Technology of Flexible AC Transmission Systems. Piscataway, New Jersey, ISBN:9780780334557, Pages: 432.

Mihirig, A.M. and M.D. Wvong, 1989. Transient stability analysis of multimachine power systems by catastrophe theory. IEEE. Proc. C Gener. Transm. Distrib., 136: 254-258.

Mithulananthan, N., C.A. Canizares, J. Reeve and G.J. Rogers, 2003. Comparison of PSS, SVC and STATCOM controllers for damping power system oscillations. IEEE Trans. Power Syst., 18: 786-792.

Papic, I. and P. Zunko, 2002. Mathematical model and steady-state operational characteristics of a unified power flow controller. Electr. Technical, Slovenija, 69: 285-290.

Patel, R., T.S. Bhatti and D.P. Kothari, 2002. MATLAB/Simulink-based transient stability analysis of a multimachine power system. Intl. J. Electr. Eng. Educ., 39: 320-336. 
Preeedavichit, P. and S.C. Srivtsava, 1998. Optimal reactive power dispatch considering facts devices. Electr. Power Syst. Res., 46: 251-257.

Sharma, C.S., 2014. Transient stability analysis of single machine infinite bus system by numerical methods. Int1. J. Electr. Electron. Res., 2: 158-166.
Xue, Y. and M. Pavella, 1993. Critical-cluster identification in transient stability studies (of power systems). Proc. C. Gener. Transm. Distrib., 140: 481-489.

Zhou, E.Z., 1993. Application of static var compensators to increase power system. IEEE Trans. Power Syst., 18: $655-661$. 